\title{
In vitro antimicrobial and in vivo antioomycete activities of the novel antibiotic thiobutacin
}

\author{
Jung Yeop Lee, ${ }^{1,2}$ David H Sherman ${ }^{2}$ and Byung Kook Hwang ${ }^{1 *}$ \\ ${ }^{1}$ Division of Biotechnology, College of Life Sciences and Biotechnology, Korea University, Seoul 136-713, Korea \\ ${ }^{2}$ Life Sciences Institute and Department of Medicinal Chemistry, College of Pharmacy, University of Michigan, 210 Washtenaw Avenue, \\ Ann Arbor, MI 48109, USA
}

\begin{abstract}
BACKGROUND: A number of synthetic fungicides are not effective when confronted by oomycete pathogens because many fungicide targets are absent from oomycetes. Moreover, resistance to fungicides has already arisen in oomycete species, and thus development of new, effective and safe compounds for use in oomycete disease control is necessary.
\end{abstract}

RESULTS: Zoospore lysis began at $10 \mu \mathrm{g} \mathrm{mL} \mathrm{mL}^{-1}$ of thiobutacin, and most of the zoospores were collapsed at $50 \mu \mathrm{g} \mathrm{mL}^{-1}$. Thiobutacin also revealed inhibitory activity against the cyst germination and hyphal growth of Phytophthora capsici at $50 \mu \mathrm{g} \mathrm{mL}^{-1}$. Treatment with thiobutacin exhibited protective activity against development of Phytophthora disease on pepper plants.

CONCLUSION: The authors verified in vitro antioomycete activity of thiobutacin against $P$. capsici and its control efficacy against Phytophthora blight in vivo. This is the first report to demonstrate in vivo antioomycete activity of the novel antibiotic thiobutacin against $P$. capsici infection. (C) 2007 Society of Chemical Industry

Keywords: thiobutacin; antimicrobial activity; antioomycete activity; Phytophthora blight

\section{INTRODUCTION}

Oomycetes have been classified in the kingdom Fungi because they apparently share morphological features, such as hyphae, appressoria, haustoria and spores, with some fungal plant pathogens. However, modern molecular and biochemical analyses suggest that oomycetes have little taxonomic affinity with filamentous fungi, but are more closely related to brown algae (heterokonts) and diatoms in the Stramenopiles, one of several major eukaryotic kingdoms. ${ }^{1,2}$ Plant-pathogenic oomycetes cause devastating diseases in numerous crop, ornamental and native plants. Synthetic fungicides such as dimethomorph, ethaboxam, famoxadone, fosetyl-aluminium, metalaxyl and propomocarb have been developed and used practically for the control of plant diseases caused by oomycetes. ${ }^{3-5}$ However, a number of synthetic fungicides are not effective when confronted by oomycete pathogens because many fungicide targets are absent from oomycetes, and present knowledge of their distinct physiology is limited. ${ }^{6}$ Moreover, resistance to fungicides has already arisen in oomycete species, ${ }^{7}$ and thus development of new, effective and safe compounds for use in oomycetes disease control is necessary.

More than 60 species of the genus Phytophthora are included in oomycetes, and they are arguably the most devastating pathogens of dicotyledonous plants. ${ }^{8}$ The Phytophthora spp. cause enormous economic damage to important crop species such as potatoes, tomatoes, peppers, soybeans and alfalfa, as well as environmental damage in natural ecosystems. ${ }^{9}$ Phytophthora blight, which is caused by Phytophthora capsici Leonian, is one of the most devastating soilborne diseases of pepper in Korea. ${ }^{10}$ Intensive studies have been concentrated on the biology of $P$. capsici, evaluation of pepper germplasm for disease resistance, yield loss assessment and the testing of chemical, biological and cultural measures of control. ${ }^{11}$

In the authors' previous search programme for microorganisms producing antioomycete and antifungal compounds useful for the control of plant diseases, the actinomycete strain VK-A9, which showed substantial antagonistic activity against plant pathogens, was isolated from soils in Korea. ${ }^{12} \mathrm{~A}$ novel antibiotic, thiobutacin [4-(2-aminophenyl)-4oxo-2-methylthiobutanoic acid] (Fig. 1), was purified

* Correspondence to: Byung Kook Hwang, Division of Biotechnology, College of Life Sciences and Biotechnology, Korea University, Seoul 136-713, Korea E-mail: bkhwang@korea.ac.kr

(Received 4 November 2006; revised version received 27 June 2007; accepted 9 August 2007)

Published online 10 December 2007; DOI: 10.1002/ps.1494 
and chemically characterized from the culture filtrate of the actinomycete strain VK-A9 by analysing NMR and MS spectral data. ${ }^{13}$ Various antifungal compounds such as manumycin-type antibiotic SW$\mathrm{B},{ }^{14}$ fistupyrone, ${ }^{15}$ phenazine-1-carboxylic acid, ${ }^{16}$ aerugine, ${ }^{17}$ A90931 $\mathrm{a}^{18}$ and staurosporine ${ }^{19}$ isolated from soil microorganisms have been demonstrated to have potent antifungal or antioomycete activity for the control of economically important plant diseases.

In the present study, the antioomycete activity of thiobutacin was examined against $P$. capsici by evaluating zoospore lysis and inhibition of cyst germination and hyphal growth in addition to in vitro bioassay for antimicrobial activity. The authors also evaluated control efficacy of thiobutacin against Phytophthora blight of pepper plants by comparison with that of the commercial oomycete fungicide metalaxyl in vivo.

\section{MATERIALS AND METHODS}

\subsection{Chemical materials}

The antibiotic thiobutacin was isolated from cultures of the strain VK-A9 as described previously. ${ }^{13}$ The oomycete fungicide metalaxyl [methyl $N$ (methoxyacetyl)-N-(2,6-xylyl)-DL-alaninate], which was obtained as technical-grade material (95\% active ingredient) from Sungbo Chemical Co., Korea, was used to compare antioomycete activity with thiobutacin in the in vitro and in vivo assays. Both thiobutacin and metalaxyl were dissolved in methanol as stock solutions to use in this study.

\subsection{Detection of in vitro antimicrobial activity}

Minimum inhibitory concentrations (MICs) of thiobutacin against fungi and bacteria were determined in a 24-well microtitre dish (Cell Wells ${ }^{\mathrm{TM}}$; Corning Glass Works, Corning, NY) using a modified version of the method of Nair et al. ${ }^{20}$ Mycelial suspension of Rhizoctonia solani Kühn, spore suspensions $\left(10^{5}\right.$ spores $\left.\mathrm{mL}^{-1}\right)$ of Alternaria mali Roberts, Cladosporium cucumerinum Ellis \& Arthur, Colletotrichum orbiculare (Berk. \& Mont.) Arx, Fusarium oxysporum Schlechtend.:Fr. f. sp. cucumerinum JH Owen and Magnaporthe grisea (TT Hebert) ME Barr and cell suspensions $\left(10^{4} \mathrm{cfu} \mathrm{mL}^{-1}\right)$ of Candida albicans (CP Robin) Berkhout, Cryptococcus neoformans (Sanfelice) Vuillemin, Bacillus subtilis (Ehrenberg) Cohn

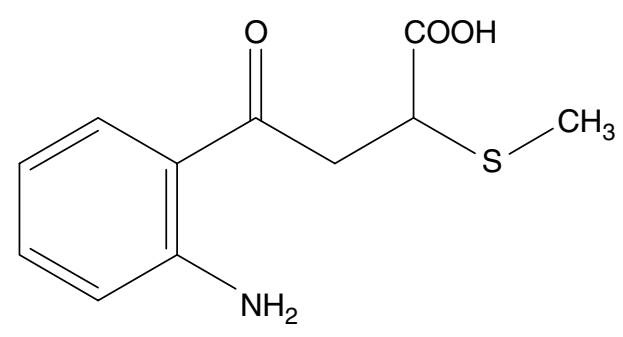

Figure 1. Structure of the antibiotic thiobutacin. subsp. subtilis, vancomycin-resistant Enterococcus faecalis (Andrewes and Horder) Schleifer and KilpperBalz (VRE), Escherichia coli (Migula) Castellani and Chalmers, Pectobacterium carotovorum subsp. carotovorum (Jones) Hauben et al., Ralstonia solanacearum (Smith) Yabuuchi et al., Staphylococcus aureus Rosenbach, methicillin-resistant $S$. aureus and Xanthomonas vesicatoria (ex Doidge) Vauterin et al. were prepared as inocula. A $100 \mu \mathrm{L}$ suspension of each inoculum was added to each well containing $0.9 \mathrm{~mL}$ of potato dextrose broth for fungi and oomycetes, LB broth for VRE, E. coli and $S$. aureus and nutrient broth for other organisms. The antibiotic thiobutacin in methanol, ranging from 0 to $100 \mu \mathrm{g} \mathrm{mL}^{-1}$, was dispensed into the microtitre plates. The antimicrobial activity of thiobutacin against the organisms was evaluated after incubation for 2-5 days. The plate inoculated with $C$. cucumerinum was incubated at $22^{\circ} \mathrm{C}$, plates inoculated with VRE, E. coli, $S$. aureus and methicillin-resistant $S$. aureus were incubated at $37^{\circ} \mathrm{C}$ and those inoculated with other microorganisms were inoculated at $28^{\circ} \mathrm{C}$. A negative control containing culture broth and microorganisms without the antibiotic was included in this test. The lowest concentrations of thiobutacin where no growth of microorganisms was observed were considered to be MICs.

\subsection{Zoospore lytic activity of thiobutacin}

The lytic activity of thiobutacin against zoospores of $P$. capsici was evaluated by counting the number of zoospores collapsed after treatment with the antibiotic at various concentrations. Zoospore suspensions were prepared from $P$. capsici cultures grown on oatmeal agar for 10 days at $28{ }^{\circ} \mathrm{C} .{ }^{21}$ Phytophthora capsici isolate 87L19, which was isolated from pepper plants in Korea and is highly sensitive to metalaxyl, was used for the assay. ${ }^{22}$ Aliquots $(0.1 \mathrm{~mL})$ of zoospore suspension $\left(1 \times 10^{6}\right.$ zoospores $\left.\mathrm{mL}^{-1}\right)$ were mixed in microtubes with $0.4 \mathrm{~mL}$ of various concentrations of thiobutacin. The number of zoospores lysed at each concentration was determined under a light microscope after incubation for $5 \mathrm{~min}$ at $28^{\circ} \mathrm{C}$. The experiments were repeated 3 times with four replicates.

\subsection{Inhibition of Phytophthora capsici cyst germination by thiobutacin}

The encystment of zoospores of $P$. capsici isolate $87 \mathrm{~L} 19$ was induced by vigorously shaking zoospore suspensions for $2 \mathrm{~min}$ at room temperature. An $0.1 \mathrm{~mL}$ aliquot of cyst suspension was dispensed in the microtube containing $0.4 \mathrm{~mL}$ of $0.5 \%$ potato dextrose broth amended with thiobutacin at each concentration. After incubation of cysts for $6 \mathrm{~h}$ at $28^{\circ} \mathrm{C}$, the cysts germinated were counted under a light microscope. The experiment was repeated 3 times with four replicates.

\subsection{Effect of thiobutacin on hyphal growth}

The suspension of zoospore cysts $(0.1 \mathrm{~mL})$ in potato dextrose broth was incubated in the microtubes at 
$28^{\circ} \mathrm{C}$, until the hyphae of the germlings had an average length of $30 \mu \mathrm{m}$. Thiobutacin or metalaxyl solution $(0.4 \mathrm{~mL})$ at various concentrations was added onto the germlings. The mixtures were then incubated at $28^{\circ} \mathrm{C}$ until the control germlings attained an average length of $400 \mu \mathrm{m}$. The length of 50 individual hyphae was determined under a light microscope. Percentage inhibition of the hyphal growth was determined by comparison of the hyphal length of the germlings treated with thiobutacin or metalaxyl with that of control germlings. Experiments with four replicates were repeated 3 times with similar results.

\subsection{In vivo evaluation of antioomycete activity of thiobutacin}

The control efficacy of the antibiotic thiobutacin against $P$. capsici infection on pepper plants was evaluated in a growth room. Pepper seeds (Capsicum annuum L. cv. Hanbyul) were sown in a plastic tray $(55 \times 35 \times 15 \mathrm{~cm})$ containing steam-sterilized soil mix (peat moss + perlite + vermiculite, $5+3+2$ by volume), sand and loam soil $(1+1+1$ by volume). Six seedling plants at the four-leaf stage were transplanted into a plastic pot $(5 \times 15 \times 10 \mathrm{~cm})$ containing the soil mix described above. Pepper plants were raised in a growth room at $28 \pm 2{ }^{\circ} \mathrm{C}$ with approximately $80 \mu \mathrm{mol}$ photons $\mathrm{m}^{-2} \mathrm{~s}^{-1}$ (white fluorescent lamps) for $16 \mathrm{~h} \mathrm{day}{ }^{-1}$. The commercial oomycete fungicide metalaxyl was used to compare the antifungal activity with thiobutacin. Solutions of thiobutacin and metalaxyl were prepared in methanol containing $0.05 \%$ Tween 20 at concentrations of 1,10 , 50,100 and $500 \mu \mathrm{g} \mathrm{mL}^{-1}$. Each solution was sprayed at $500 \mathrm{~L} \mathrm{ha}^{-1}$ onto the surface of pepper plants at the first-branch stage 1 day before inoculation with P. capsici isolate $87 \mathrm{~L} 19$. Control plants were sprayed with Tween 20 solution without chemical. The pepper plants treated with thiobutacin and metalaxyl were wounded by making $1 \mathrm{~cm}$ longitudinal slits on the stems $1 \mathrm{~cm}$ from the soil surface. The zoospore suspension was prepared as described previously. ${ }^{21}$ Sterile cotton dipped in a zoospore suspension $\left(10^{5}\right.$ zoospores $\mathrm{mL}^{-1}$, prepared as described previously ${ }^{21}$ ) was placed on the wounded sites on the stem. The inoculated sites were covered with plastic tape to maintain a moist condition. Disease severity on pepper plants was rated daily after inoculation on the basis of a scale $0-5: 0=$ no visible disease symptoms; $1=$ leaves slightly wilted with brownish lesions beginning to appear on stems; $2=30-50 \%$ of entire plant diseased; $3=50-70 \%$ of entire plant diseased; $4=70-90 \%$ of entire plant diseased; $5=$ plant dead. Data are the means of six plants per treatment.

\section{RESULTS AND DISCUSSION}

The novel antibiotic thiobutacin has been chemically characterized and demonstrated to have in vitro antioomycete activity against $P$. capsici in a previous study by the authors. ${ }^{13}$ In the present study, assays were performed to evaluate the in vitro antimicrobial activity of thiobutacin against diverse fungi and bacteria. The antibiotic thiobutacin completely inhibited the mycelial growth of C. cucumerinum at $50 \mu \mathrm{g} \mathrm{mL}^{-1}$ (Table 1 ), as well as the oomycete pathogen $P$. capsici (MIC $10 \mu \mathrm{g} \mathrm{mL}^{-1}$ ) and B. cinerea (MIC $50 \mu \mathrm{g} \mathrm{mL}^{-1}$ ) as previously reported. ${ }^{13}$ However, the growth of $A$. mali, C. orbiculare, F. oxysporum f. sp. cucumerinum, $M$. grisea and $R$. solani was not inhibited even at $100 \mu \mathrm{gLL}^{-1}$, and nor was the cell growth of $C$. albicans and $C$. neoformans affected at $100 \mu \mathrm{g} \mathrm{mL}^{-1}$. Thiobutacin also showed antibacterial activity against $S$. aureus and methicillin-resistant $S$. aureus with MICs of 25 and $50 \mu \mathrm{g} \mathrm{mL}^{-1}$ respectively. No other bacterial growth inhibition was observed at $100 \mu \mathrm{g} \mathrm{mL}^{-1}$.

To evaluate zoospore lysis activity of the antibiotic thiobutacin, zoospore suspensions of $P$. capsici treated with thiobutacin were examined under a light microscope over a time sequence. Zoospores were rendered immotile within $10-15 \mathrm{~s}$ following exposure to thiobutacin $\left(50 \mu \mathrm{g} \mathrm{mL}^{-1}\right)$, and subsequent lysis started to occur at $60 \mathrm{~s}$ (Fig. 2A). The zoospores of $P$. capsici began to swell and eventually ruptured at $60 \mathrm{~s}$ after treatment with thiobutacin, and complete lysis of zoospores occurred at $90 \mathrm{~s} \mathrm{(Fig.} \mathrm{2B).} \mathrm{Compared} \mathrm{with}$ the untreated control, zoospore motility was distinctly

Table 1. Minimum inhibitory concentrations (MIC) of thiobutacin against various microorganisms as determined by the microtitre broth dilution method

\begin{tabular}{|c|c|c|}
\hline Microorganism & $\begin{array}{c}\mathrm{MIC} \\
\left(\mu \mathrm{g} \mathrm{mL}^{-1}\right)^{a, b}\end{array}$ & Reference \\
\hline \multicolumn{3}{|l|}{ Fungus and oomycete } \\
\hline Alternaria mali & $>100$ & Present study \\
\hline Botrytis cinerea & 50 & 13 \\
\hline Cladosporium cucumerinum & 50 & Present study \\
\hline Colletotrichum orbiculare & $>100$ & Present study \\
\hline Fusarium oxysporum f. sp. & $>100$ & Present study \\
\hline cucumerinum & & \\
\hline Magnaporthe grisea & $>100$ & Present study \\
\hline Phytophthora capsici & 10 & 13 \\
\hline Rhizoctonia solani & $>100$ & Present study \\
\hline Candida albicans & $>100$ & Present study \\
\hline Cryptococcus neoformans & $>100$ & Present study \\
\hline Saccharomyces cerevisiae & 30 & 13 \\
\hline \multicolumn{3}{|l|}{ Bacterium } \\
\hline Bacillus subtilis subsp. subtilis & $>100$ & Present study \\
\hline Vancomycin-resistant & $>100$ & Present study \\
\hline \multicolumn{3}{|l|}{ Enterococcus faecalis } \\
\hline Escherichia coli & $>100$ & Present study \\
\hline Pectobacterium carotovorum & $>100$ & Present study \\
\hline \multicolumn{3}{|l|}{ subsp. carotovorum } \\
\hline Ralstonia solanacearum & $>100$ & Present study \\
\hline Staphylococcus aureus & 25 & Present study \\
\hline Methicillin-resistant & 50 & Present study \\
\hline \multicolumn{3}{|l|}{ Staphylococcus aureus } \\
\hline Xanthomonas vesicatoria & $>100$ & Present study \\
\hline
\end{tabular}

a The lowest concentration of thiobutacin required for complete inhibition of microbial growth.

b $>100$ indicates that growth of the microorganisms was not completely inhibited at $100 \mu \mathrm{g} \mathrm{mL}^{-1}$. 

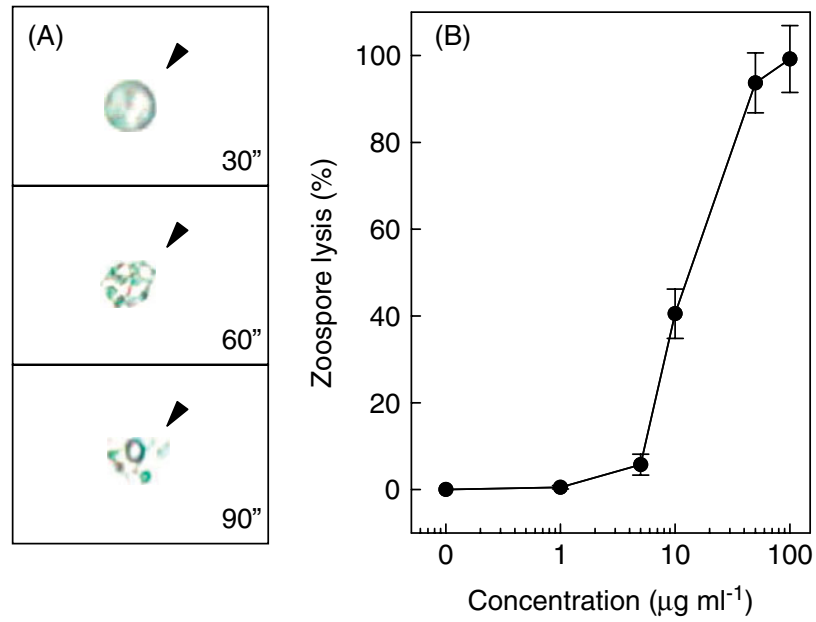

Figure 2. The lytic activity of thiobutacin against zoospores of Phytophthora capsici. (A) Time course of zoospore lysis after exposure to thiobutacin $\left(50 \mu \mathrm{g} \mathrm{mL}^{-1}\right)$, examined under a light microscope (magnification, $\times 100$ ). (B) The zoospore lysis activity of thiobutacin at various concentrations. The experiments were repeated 3 times with four replicates. Vertical bars represent standard errors.

reduced at $5 \mu \mathrm{g} \mathrm{mL}^{-1}$ of thiobutacin, although a weak zoospore lytic activity was observed (data not shown). Most zoospores were lysed at $100 \mu \mathrm{g} \mathrm{mL}^{-1}$ of thiobutacin.

Zoospores have been accepted as the principal dispersive agents of oomycetes. Therefore, zoospore movement and encystment are important factors in the pathogenicity of oomycete pathogens such as Phytophthora and Pythium spp. ${ }^{23}$ The zoospore seems to be not only the most susceptible phase in the life cycle of zoosporogeneric fungi, but also the stage at which disease control could be efficient. ${ }^{24}$ The zoospores may not be strong enough to bear osmotic pressure of water under conditions where active transport is inhibited, thus resulting in plasma membrane rupture, because zoospores do not have cell walls, only plasma membranes. ${ }^{25}$ The authors previously demonstrated that rhamnolipid $\mathrm{B}$ isolated from Pseudomonas aeruginosa (Schroeter) Migula and phenylacetic acid produced by Streptomyces humidus Nakazawa and Shibata had lytic effects on zoospores as well as inhibitory activity against the cyst germination and hyphal growth of $P$. capsici. ${ }^{26,27}$ Some natural products, such as anacardic acid from Ginkgo biloba L. ${ }^{6}$ and phytuberin from potato tubers, ${ }^{28}$ also exhibited antioomycete activity against Phytophthora infestans (Montagne) de Bary, resulting in the lysis of the zoospores. Cyst germination was completely inhibited after treatment with thiobutacin at $50 \mu \mathrm{g} \mathrm{mL}^{-1}$ (Fig. 3A). Thiobutacin strongly inhibited the hyphal growth of $P$. capsici at 50 and $100 \mu \mathrm{g} \mathrm{mL}^{-1}$ (Fig. 3B). The average hyphal length of germlings was reduced at $50 \mu \mathrm{g} \mathrm{mL}^{-1}$ to $58 \%$ of that in the untreated control.

In the present study it was shown that the antibiotic thiobutacin inhibited some stages of the life cycle of $P$. capsici, including zoospore motility, cyst germination and hyphal growth. It has been demonstrated that zoospore motility and release are affected by inhibition of the energy supply. ${ }^{29}$ Energy generation-inhibitory molecules such as fluazinam and famoxadone inhibit zoospore motility and release in $P$. infestans, ${ }^{30,31}$ while non-respiratory inhibitors, such as metalaxyl and dimethomorph, cause little or no inhibition of zoospore motility and release of $P$. infestans. ${ }^{32,33}$ Further detailed studies are required to determine whether thiobutacin impairs the energy generation system in P. capsici.

In vivo control efficacy of thiobutacin for the suppression of Phytophthora blight on pepper plants was evaluated under greenhouse conditions (Fig. 4). As the concentration of the antibiotic thiobutacin and commercial fungicide metalaxyl increased, the development of Phytophthora blight was gradually inhibited on the pepper plants at the first-branch stage. Phytophthora disease symptoms were markedly reduced by treatment with 100 or $500 \mu \mathrm{g} \mathrm{mL}^{-1}$ of the two compounds. The control efficacy of thiobutacin against Phytophthora blight was in general less than

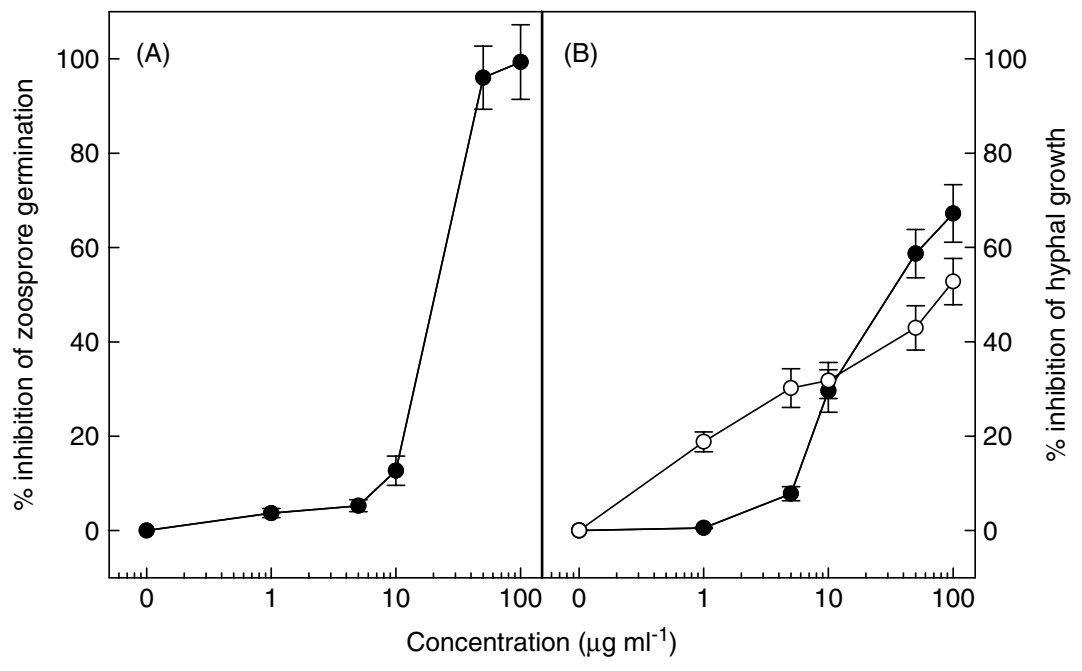

Figure 3. (A) Inhibitory effect of thiobutacin on cyst germination. (B) Inhibitory effects of (O) thiobutacin and (O) metalaxyl on hyphal growth of Phytophthora capsici at various concentrations. The experiments were repeated 3 times with four replicates. Vertical bars represent standard errors. 


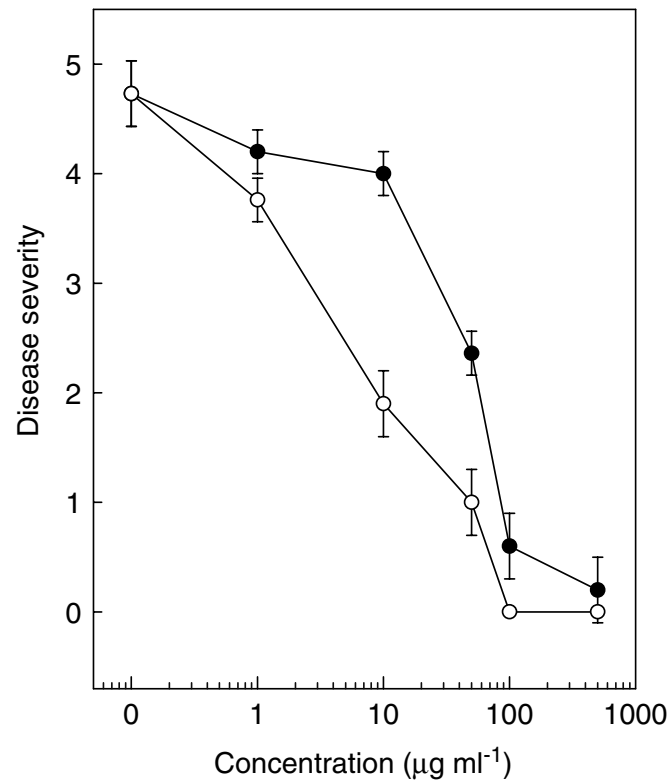

Figure 4. Effects of $(0)$ thiobutacin and $(0)$ metalaxyl on disease development in pepper plants inoculated with Phytophthora capsici at the first-branch stage. Disease severity is based on a 0-5 scale, where $0=$ no visible symptom and $5=$ plant dead. Data are the means of six plants per treatment. Vertical bars represent standard errors.

that of metalaxyl on pepper plants. However, in vivo efficacy of thiobutacin was not significantly different from that of metalaxyl at $500 \mu \mathrm{g} \mathrm{mL}^{-1}$. Thiobutacin did not induce any phytotoxicity on pepper plants, even when treated with $500 \mu \mathrm{g} \mathrm{mL}^{-1}$ (data not shown).

In many cases, in vivo control efficacy of antibiotics against plant diseases correlates with their in vitro activity. ${ }^{34}$ The present study ascertained not only the in vitro antimicrobial activity of thiobutacin but also its in vivo antioomycete activity in the host plants. These results suggest that the antibiotic thiobutacin may have a potent chemotherapy against $P$. capsici infection. To the authors' knowledge, this is the first report to demonstrate in vivo efficacy of thiobutacin for the control of Phytophthora blight in pepper plants. The finding that thiobutacin has antioomycete activity may enable it to be used as a lead for developing agricultural fungicides for the control of plant oomycete diseases such as Phytophthora blight.

In conclusion, the antibiotic thiobutacin has not only a potent in vitro antioomycete activity against $P$. capsici but also in vivo control efficacy against Phytophthora disease on pepper. Further studies on the mechanism of action of thiobutacin at the molecular level and field evaluation of its effectiveness for disease control and the design of applications for its practical use should be done.

\section{ACKNOWLEDGEMENTS}

This work was supported by a grant (CG1133) from the Crop Functional Genomics Centre of the Twentyfirst Century Frontier Research Programme, a grant from the Centre for Plant Molecular Genetics and
Breeding Research, Seoul National University, Korea, and a grant (20070401034028) from the BioGreen21 Programme, Rural Development Administration, Korea.

\section{REFERENCES}

1 Baldauf SL, Roger AJ, Wenk-Siefert I and Doolittle WF, A kingdom-level phylogeny of eukaryotes based on combined protein data. Science (Washington) 290:972-977 (2000).

2 Sogin ML and Silberman JD, Evolution of the protists and protistan parasites from the perspective of molecular systematics. Internat f Parasitol 28:11-20 (1998).

3 Cohen Y and Coffey MD, Systemic fungicides and the control of oomycetes. Ann Rev Phytopathol 24:311-338 (1986).

4 Sternberg JA, Geffken D, Adams JB, Pöstages R, Sternberg CG, Campbell CL, et al, Famoxadone: the discovery and optimisation of a new agricultural fungicide. Pest Manag Sci 57:143-152 (2001).

5 Kim DS, Chun SJ, Jeon JJ, Lee SW and Joe GH, Synthesis and fungicidal activity of ethaboxam against oomycetes. Pest Manag Sci 60:1007-1012 (2004).

6 Begum P, Hashidoko Y, Islam MT, Ogawa Y and Tahara S, Zoosporicidal activities of anacardic acids against Aphanomyces cochlioides. Z Naturforsch 57:874-882 (2002).

7 Gisi U and Cohen Y, Resistance to phenylamide fungicides: a case study with Phytophthora infestans involving mating type and race structure. Annu Rev Phytopathol 34:549-572 (1996).

8 Erwin DC and Ribeiro OK, Phytophthora Disease Worldwide. APS Press, St Paul, MN, USA (1996).

9 Kamoun S, Molecular genetics of pathogenic oomycetes. Eukaryot Cell 2:191-199 (2003).

$10 \mathrm{Kim} \mathrm{CH}$, Current status of fungal and bacterial disease of hot pepper and their control measures. F Korean Capsicum Res Coop 2:1-11 (1993).

11 Hwang BK and Kim CH, Phytophthora blight of pepper and its control in Korea. Plant Dis 79:221-227 (1995).

12 Lee JY and Hwang BK, Diversity of antifungal actinomycetes in various vegetative soils of Korea. Can F Microbiol 48:407-417 (2002).

13 Lee JY, Moon SS, Yun BS, Yoo ID and Hwang BK, Thiobutacin, a novel antifungal and antioomycete antibiotic from Lechevalieria aerocolonigenes. F Nat Prod 67:2076-2078 (2004).

14 Hwang BK, Lee JY, Kim BS and Moon SS, Isolation, structure elucidation, and antifungal activity of a manumycin-type antibiotic from Streptomyces flaveus. I Agric Food Chem 44:3653-3657 (1996).

15 Igarashi Y, Ogawa M, Sato Y, Saito N, Yoshida R, Kunoh H, et al, Fistupyrone, a novel inhibitor of the infection of Chinese cabbage by Alternaria brassicicola, from Streptomyces sp. TPA0569. F Antibiot 53:1117-1122 (2000).

16 Lee JY, Moon SS and Hwang BK, Isolation and in vitro and in vivo activity against Phytophthora capsici and Colletotrichum orbiculare of phenazine-1-carboxylic acid from Pseudomonas aeruginosa strain GC-B26. Pest Manag Sci 59:872-882 (2003).

17 Lee JY, Moon SS and Hwang BK, Isolation and antifungal and antioomycete activities of aerugine produced by Pseudomonas fluorescens strain MM-B16. Appl Environ Microbiol 69:2023-2031 (2003)

18 Graupner PR, Thornburgh S, Mathieson JT, Chapin EL, Kemmitt GM, Brown JM, et al, Dihydromaltophilin: a novel fungicidal tetramic acid containing metabolite from Streptomyces $\mathrm{sp}$. F Antibiot 50:1014-1019 (1997).

19 Park HJ, Lee JY, Hwang IS, Yun BS, Kim BS and Hwang BK, Isolation and antifungal and antioomycete activities of staurosporine from Streptomyces roseoflavus strain LS-A24. f Agric Food Chem 54:3041-3046 (2006).

20 Nair MG, Mishra SK and Putnam AR, Antifungal anthracycline antibiotics, spartanamicins A and B from Micromonospora spp. f Antibiot 45:1738-1745 (1992). 
21 Kim YJ, Hwang BK and Park KW, Expression of age-related resistance in pepper plants infected with Phytophthora capsici. Plant Dis 73:745-747 (1989).

22 Lee BK, Kim BS, Chang SW and Hwang BK, Aggressiveness to pumpkin cultivars of isolates of Phytophthora capsici from pumpkin and pepper. Plant Dis 85:497-500 (2001).

23 Hickman CJ, Biology of Phytophthora zoospores. Phytopathology 60:1128-1135 (1970).

24 Lange L and Olson LW, The fungal zoospore, in Zoosporic Plant Pathogens: A Modern Perspective, ed. by Buczacki ST Academic Press, London, UK, pp. 1-42 (1983)

25 Mitani S, Araki S, Yamaguchi T, Takii Y, Ohshima $\mathrm{T}$ and Matsuo N, Antifungal activity of the novel fungicide cyazofamid against Phytophthora infestans and other plant pathogenic fungi in vitro. Pestic Biochem Physiol 70:92-99 (2001).

26 Lee JY, Kim HS, Kim KD and Hwang BK, In vitro antioomycete activity and in vivo control efficacy of phenylacetic acid against Phytophthora capsici. Plant Pathol f 20:177-183 (2004).

27 Kim BS, Lee JY and Hwang BK, In vivo control and in vitro antifungal activity of rhamnolipid B, a glycolipid antibiotic, against Phytophthora capsici and Colletotrichum orbiculare. Pest Manag Sci 56:1029-1035 (2000).
28 Harris JE and Dennis C, Antifungal activity of post-infectional metabolites from potato tubers. Physiol Plant Pathol 9:155-165 (1976).

29 Ziogas BN and Davidse LC, Studies on the mechanism of action of cymoxanil in Phytophthora infestans. Pestic Biochem Physiol 29:89-96 (1987).

30 Cooke LR, Little G and Wilson DG, Sensitivity of Phytophthora infestans to fluazinam and its use in potato blight control in Northern Ireland. Proc Brighton Crop Prot Conf-Pests and Diseases, BCPC, Alton, Hants, UK, pp. 517-522 (1998).

31 Jordan DB, Livingston RS, Bisaha JJ, Duncan KE, Pember SO, Picollelli MA, et al, Mode of action of famoxadone. Pestic Sci 55:105-118 (1999).

32 Bruck RI, Fry WE and Apple AE, Effect of metalaxyl, an acrylalanine fungicide, on developmental stages of Phytophthora infestans. Phytopathology 70:597-601 (1980).

33 Cohen Y, Baider A and Cohen B, Dimethomorph activity against oomycete fungal plant pathogens. Phytopathology 85:1500-1506 (1995).

34 Howie WJ and Suslow TV, Role of antibiotic biosynthesis in the inhibition of Pythium ultimum in the cotton spermosphere and rhizosphere by Pseudomonas fluorescens. Mol Plant-Microbe Interact 4:393-399 (1991). 